\title{
Comparative Metagenomics of Viral Assemblages Inhabiting Four Phyla of Marine Invertebrates
}

\author{
Brent M. Gudenkauf and lan Hewson * \\ Department of Microbiology, Cornell University, Ithaca, NY, USA
}

Viruses are the most abundant biological entities on Earth, killing 10-20\% of oceanic biomass each day. However, despite their ecological importance, viruses inhabiting many echinoderms, cnidarians, urochordates, and marine arthropods have not been investigated with significant breadth. We conducted a broad survey of the viral assemblages inhabiting these hosts through viral metagenomics and phylogenetic analysis. Results indicate that different invertebrate groups harbor distinct viral assemblages. Interestingly, however, no significant difference is observed between the viral assemblages of echinoderms and arthropods. These similarities and differences may be due to cellular, immunological, geographical, and ecological differences amongst

\section{OPEN ACCESS}

Edited by:

Rex Malmstrom,

U.S. Department of Energy Joint Genome Institute, USA

Reviewed by:

Karen Dawn Weynberg, Australian Institute of Marine Science, Australia

Rebecca Lisette Vega Thurber, Oregon State University, USA

*Correspondence: lan Hewson hewson@cornell.edu

Specialty section: This article was submitted to Aquatic Microbiology, a section of the journal Frontiers in Marine Science

Received: 14 November 2015 Accepted: 22 February 2016 Published: 10 March 2016

Citation:

Gudenkauf BM and Hewson I (2016) Comparative Metagenomics of Viral Assemblages Inhabiting Four Phyla of

Marine Invertebrates.

Front. Mar. Sci. 3:23.

doi: 10.3389/fmars.2016.00023 host phyla, although mechanistic determination is beyond the purview of this work. Additionally, we present evidence of the detection of several viral families that have not yet been observed in these hosts. Finally, we confirm the result of previous investigation that method of library construction significantly biases metagenomic results by altering the representation of SsDNA and dsDNA viral genomes.

Keywords: virus, invertebrate, circovirus, metazoa, zooplankton

\section{INTRODUCTION}

Viruses are the most abundant biological entities on Earth, with an estimated $10^{30}$ viruses in the oceans (Suttle, 2007). Surface seawater typically harbors $10^{7}$ viral particles $\mathrm{mL}^{-1}$, with fewer viruses at depth $\left(10^{5} \mathrm{~mL}^{-1}\right)$, and greater abundance in algal blooms (Wommack and Colwell, 2000). These viruses cause mortality in $10-20 \%$ of oceanic biomass each day (Munn, 2006; Suttle, 2007). Viruses associated with metazoan host microbiomes include viruses that infect hosts (i.e., pathogens, neutral-effect viruses, and endogenous viruses), and also viruses that infect non-metazoan components, including bacterial, archaeal, and eukaryotic microbial constituents.

Despite their significance as agents of mortality, investigation of viruses associated with marine invertebrates has historically been limited. Viruses of many ecologically important marine invertebrate faunae have not yet been investigated; Entire phyla lack described viruses (Suttle, 2005). This is due to several obstacles that make conventional investigation difficult. For instance, cell lines that model marine invertebrate metazoan tissues are unavailable, and cell culturing techniques are incompatible with microbes that have unknown growth requirements or require symbioses. Metagenomics allows investigators to overcome some of these obstacles via next generation shotgun-sequencing, targeting nucleic acids to observe entire microbial communities. Recent viral metagenomic studies have exposed novel families of invertebrate viruses (e.g., Ng, 2010; Rosario et al., 2011, 2012; Dunlap et al., 2013). This technique may be used as 
viral surveillance (Ng, 2010), or as a starting point for further investigation into microbe-microbe interactions, microbe-host interactions, pathogenesis, and disease diagnosis. The lack of representative viral genomes in public databases may decrease confidence in metaviromes annotation (Weynberg et al., 2014). However, metaviromics provides a strong starting point for future study of viral-host relationships.

Echinoderms, cnidarians, urochordates, and arthropods are ecologically important benthic marine invertebrates. Many are keystone species, disproportionately affecting ecological structure through predation and consumption (Paine, 1969). Others are filter-feeders, clarifying water by altering turbidity and light penetration by controlling local populations of free-floating microbes and particulate matter (Berke, 2010). Still others are decomposers and participate in bioturbation, oxygenating anoxic sediments, and releasing stored nutrients into the water column. Because benthic invertebrates play important roles in marine habitat ecology and biogeochemistry, investigation into the viral diversity of their microbiomes is relevant to understanding how viruses influence marine ecosystems. There have been few reports of viruses of echinoderms (Gudenkauf et al., 2014; Hewson et al., 2014), very few of non-commercially important (but ecologically important) marine arthropods (e.g., Dunlap et al., 2013), only one of viruses infecting non-scleractinian corals (Hewson et al., 2011a), and no previous reports of viruses inhabiting urochordates.

While most populations of echinoderms are long-lived in the absence of pathogenic agents (Bluhm et al., 1998), bacteria and protozoan parasites can cause mortality (Jangoux, 1987). However, there are some instances of mass mortality that remain unexplained by bacteria or protozoan influences alone and for which viruses are the most likely factor. For instance, a mass mortality event of the echinoid Diadema antillarum occurred starting in 1983 . Death of $97 \%$ of the population occurred rapidly throughout the Caribbean, with infection radiating outward from a locus at the Panama Canal. While these characteristics alone resemble classical elements of viral epidemiology, the most striking resemblance lies in the fact that infection was transmissible by material $<0.2 \mu \mathrm{m}$ in size, which is smaller than the smallest known bacterial genus, Mycoplasma (Lessios et al., 1984; Lessios, 1988). The loss of D. antillarum profoundly affected the ecology of reef ecosystems within the Caribbean as macroalgae became overgrown, inhibiting coral growth and contributing to further decline of scleractinian corals (Carpenter, 1990).

Asteroids have also been decimated by several stillunexplained mass mortality events off the coast of California since 1978 (Bates et al., 2009). Recently, a densovirus (the sea star associated densovirus or SSaDV) was identified as the most likely cause of the most recent sea star "wasting disease" that occurred in 2013 and 2014 along the western coast of North America (Hewson et al., 2014). Gorgonian sea fans and tunicates also underwent a mass-mortality event in the northwest Mediterranean Sea in the summer of 1999, with this event correlating with higher than average oceanic temperatures (Cerrano et al., 2000). This correlation may support a switch from commensal to pathogenic microorganisms. However, this does not explain those events in which oceanic temperatures were not above normal, like the sea star wasting event. While the sudden decline of echinoderm populations may be related to environmental shifts (e.g., restricted water flow, anoxia, or slight changes in temperature), collapse in the absence of great physical change is consistent with viral or other pathogen attack.

With this work we seek to characterize the viruses found in the tissues of echinoderms, marine arthropods, cnidarians, and urochordates and compare the assemblages to identify common constituents within different host phyla. We attempt to answer the question: Do similar viruses inhabit broad host taxa, or do different taxa host distinct viruses?

\section{METHODS}

\section{Sampling}

All samples were adults (i.e., no juveniles or larvae) and were collected by snorkel (Peramphithoe femorata), SCUBA diving (Gorgonia ventalina), from an artisanal fish market (Pyura chilensis), or by hand in the intertidal zone (arthropoda species) (Table 1). Data from asteroids and echinoids were collected as part of two previous studies (Gudenkauf et al., 2014; Hewson et al., 2014). In all cases, samples were immediately placed into Whirlpak ${ }^{\odot}$ bags and frozen.

\section{Metagenomic Library Preparation}

We prepared 41 viromes from four phyla of marine invertebrates following the approach of $\mathrm{Ng}$ et al. (2009). Invertebrate tissue samples were removed from storage at $-80^{\circ} \mathrm{C}$ and thawed. Once at room temperature, we amended tissues with $20 \mathrm{~mL}$ of $0.02 \mu \mathrm{m}$ filtered phosphate buffered saline and ground them in a sterile mortar and pestle. Homogenates were centrifuged for $10 \mathrm{~min}$ at $5000 \times \mathrm{g}$ to remove large particulate material. Next, we syringefiltered the supernatant $(0.2 \mu \mathrm{m}$ Polyethersulfone) to remove cell debris and bacteria-size particles. Then, we amended filtrates with polyethylene glycol 8000 ( $10 \%$ weight-to-volume), mixed by inversion for $1 \mathrm{~min}$, and precipitated them overnight at $4^{\circ} \mathrm{C}$. Following precipitation, samples were centrifuged for $45 \mathrm{~min}$ at $12,000 \times \mathrm{g}$. Next we removed supernatants by pipette and suspended viral pellets in $1 \mathrm{~mL}$ nuclease-free deionized water. Resuspended pellets were extracted with $200 \mu \mathrm{L} \mathrm{CHCl} 3$, inverted to mix, and allowed to settle for $10 \mathrm{~min}$ at room temperature. Subsequently we centrifuged samples for $1 \mathrm{~min}$ at $15,000 \times \mathrm{g}$ and transferred the aqueous layer to a new tube. Invitrogen TURBO DNase (14 U), Promega RNase One (20 U), $1 \mu \mathrm{L}$ of Benzonase Nuclease, and $11.5 \mu \mathrm{L}$ of nuclease-free deionized water were added to each sample, which were then incubated in a water bath at $37^{\circ} \mathrm{C}$ for $3 \mathrm{~h}$. After incubation, we added $20 \mu \mathrm{mol}$ EDTA to each sample, which we then stored at $-80^{\circ} \mathrm{C}$.

We confirmed the absence of bacterial and eukaryotic genomic DNA by PCR targeting $16 \mathrm{~S}$ and $18 \mathrm{~S}$ genes (Thurber et al., 2009). Next, we extracted DNA from purified viruses using Zymo Research Viral DNA Kit and amplified viral DNA using the GenomePlex Whole Genome Amplification (WGA2) kit (SigmaAldrich), or for the case of $P$. chilensis, we used both WGA2 and GenomiPhi $\$ 29$ HY DNA Amplification kits (Illustra) to compare the effects of amplification strategy on library 
TABLE 1 | Sample details for Arthropoda, Echinodermata, Chordata, and Cnidaria samples used in metagenomic analyses.

\begin{tabular}{|c|c|c|c|c|c|c|c|}
\hline Species & Phylum & Class & Location & Date & Latitude $\left({ }^{\circ}\right)$ & Longitude $\left({ }^{\circ}\right)$ & Depth (m) \\
\hline Acanthaster planci & Echinodermata & Asteroidea & Big Island, Hawaii & $8 / 4 / 13$ & 19.7056 & -155.0858 & 3 \\
\hline Orchestoidea californiana & Arthropoda & Maxillopoda & $\begin{array}{l}\text { Big Fisherman's Cove, Santa } \\
\text { Catalina Island }\end{array}$ & 2/13/13 & 33.6269 & -118.5141 & Intertidal \\
\hline Peramphithoe femorata & Arthropoda & Maxillopoda & $\begin{array}{l}\text { Big Fisherman's Cove, Santa } \\
\text { Catalina Island }\end{array}$ & 2/13/13 & 33.6269 & -118.5141 & 1 \\
\hline Neotrypaea californiensis & Arthropoda & Malacostraca & $\begin{array}{l}\text { Little Fisherman's Cove, Santa } \\
\text { Catalina Island }\end{array}$ & $2 / 12 / 13$ & 33.4400 & -118.4992 & Intertidal \\
\hline Halocaridina rubra & Arthropoda & Malacostraca & Big Island, Hawaii & $1 / 10 / 13$ & 19.9154 & -155.8874 & Freshwater \\
\hline Gorgonia ventalina (healthy) & Cnidaria & Anthozoa & Puerto Rico & $9 / 8 / 13$ & 18.2011 & -67.1397 & 12 \\
\hline Gorgonia ventalina (diseased) & Cnidaria & Anthozoa & Puerto Rico & $9 / 8 / 13$ & 18.2011 & -67.1397 & 12 \\
\hline Pyura chilensis 1 & Chordata & Ascidiacea & Valpariso, Chile & $11 / 19 / 13$ & -33.0500 & -71.6167 & Unknown \\
\hline Pyura chilensis 2 & Chordata & Ascidiacea & Valpariso, Chile & $11 / 19 / 13$ & -33.0500 & -71.6167 & Unknown \\
\hline Pyura chilensis 3 & Chordata & Ascidiacea & Valpariso, Chile & $11 / 19 / 13$ & -33.0500 & -71.6167 & Unknown \\
\hline Pyura chilensis 4 & Chordata & Ascidiacea & Valpariso, Chile & $11 / 19 / 13$ & -33.0500 & -71.6167 & Unknown \\
\hline Pyura chilensis 5 & Chordata & Ascidiacea & Valpariso, Chile & $11 / 19 / 13$ & -33.0500 & -71.6167 & Unknown \\
\hline
\end{tabular}

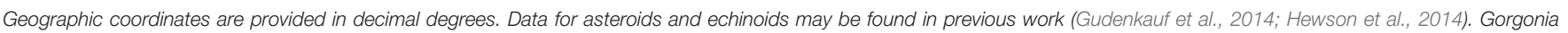
ventalina samples are denoted as healthy or diseased based on the presence of lesions.

composition. Next, we used the Zymo Research DNA Clean and Concentrator kit to purify amplicons. Whole genome amplicons were sequenced with Illumina MiSeq $2 \times 250$ bp paired-end chemistry at Cornell University Core Sequencing Center, where each sample was multiplexed with other samples. Sequence libraries have been deposited at GenBank SRA under accession numbers SAMN03653376, SAMN03653669, SAMN03653670, and SAMN03653673-SAMN03653676. Data from 28 asteroid samples (Hewson et al., 2014) and data from three echinoid samples (Gudenkauf et al., 2014) were included as part of this analysis.

\section{Metagenomic Analyses}

We imported resulting forward and reverse Illumina read sequences into CLC Genomics Workbench 4.0 and conducted de novo assembly on sequence reads using an assembly algorithm (length fraction 0.5 , similarity 0.8 , global alignment, vote on uncertain nucleotides, non-specific-matches randomized, and minimum contiguous sequence length of 500 nucleotides), generating contiguous fragments (contigs). Duplicate reads made up only a small percentage of reads within each library. Next, we identified open reading frames on contiguous sequences using the GetORF algorithm (EMBOSS) and subjected the resulting sequences to BLASTx analysis against the NCBI non-redundant (nr) protein database at the Cyberinfrastructure for Advanced Microbial Ecology Research and Analysis (CAMERA2). The strongest ORF similarity (i.e., lowest $E$-value, with an $E$-value cutoff of 0.001) per contig was used in further analyses.

\section{Statistical Analysis}

Two analyses of metagenomic composition were performed. First, we noted the number of assembled contigs per identified organism for quantitative statistical analyses on virome composition. The relative proportion of each viral genotype within a particular library was calculated as a percentage of the total number of viral genotypes identified in the library. Next, we binned viral genotypes at the family level of phylogeny. Then, we calculated a Bray-Curtis pairwise similarity matrix between libraries using XLSTAT (Addinsoft SARL) and heat mapping on the similarity matrix to permit visualization of the similarity of viral metagenomic compositions. Next, we performed two-dimensional scaling analysis (absolute model, Kruskal's stress, random initial configuration, five repetitions, stop condition at 0.00001 convergence/500 iterations) and agglomerative hierarchical clustering (unweighted pair-group average, automatically truncated) on non-bacteriophage annotations (also not including unclassified viruses). We also calculated mean similarity (by averaging Bray-Curtis similarity index values) and standard error between and across the host phyla studied both including and removing bacteriophage sequences.

\section{Phylogenetic Analysis}

Three groups of eukaryotic viruses that were observed in viromes from multiple host phyla were chosen for phylogenetic analysis. These groups consisted of viruses from families Parvoviridae, Circoviridae, and Phycodnaviridae. The phylogeny of the viral sequence with the greatest representation in each library was determined by comparison with the closest BLASTx match against the RefSeq Database at NCBI. Metagenomic sequences and their closest matches in GenBank were aligned using CLUSTALW (Thompson et al., 1994) and bootstrapped phylogenetic trees (1000 iterations) were drawn by the Neighbor Joining algorithm (complete linkage) and visualized using TREEVIEW (Page, 1996). Trees were rooted with an evolutionarily distant out-group.

\section{RESULTS AND DISCUSSION}

\section{Metagenomic Annotation}

Illumina sequence reads varied from about 180 to $600 \mathrm{bp}$ and sequencing of viromes prepared from echinoderms, arthropods, 
cnidarians, and urochordates yielded between 33,673 and $1,677,426$ contiguous sequence per library (Table 2). Of these, between 0.06 and $88.03 \%$ matched viral genomes, with the remaining sequences corresponding to bacterial, archaeal, or eukaryotic genome fragments. This is similar to the results of previous studies that utilized similar viral genome isolation protocols, and likely results from DNA released from host, bacterial, and/or archaeal cells during the tissue homogenization process (Hewson et al., 2011a, 2013; Gudenkauf et al., 2014). The low number of viral annotations may be a result of lack of representative viral genomes in public databases (Weynberg et al., 2014). The wide range of contig sequences could have resulted from differences in host tissue mass, amounts of mucosal epithelia from which viruses were extracted, or from differences in viral load.

\section{Overview of Viral Metagenomic Composition}

Thirty-four viral families were represented within 41 viromes. Pisaster ochraceus (diseased 2, Santa Cruz) and Pycnopodia helianthoides (diseased 2, Seattle Aquarium), members of the Echinodermata phylum, harbored the most diverse viral assemblages, with 15 viral families represented in each. Evasterias troscheli (healthy, Friday Harbor Lab) and P. helianthoides (healthy, Friday Harbor Lab), also echinoderms, had the least diverse viral assemblages, with only two families represented in each virome.

Bacteriophage comprised the vast majority of viral annotations in all samples (Figure 1). This is not surprising, as bacteria exist within healthy epithelial tissues of echinoderms (Becker et al., 2007, 2009), on healthy cnidarian sea fan tissues (Gil-Agudelo et al., 2006), within epithelial and hepatopancreatic tissue of decapoda (Goffredi et al., 2008; Guri et al., 2012; Nunan et al., 2013), within healthy epithelial tissues of amphipoda
(Mengoni et al., 2013), and tunicates (Pérez-Matos et al., 2007). Because the surfaces of the metazoans were not cleaned or scrubbed prior to tissue amendment, some of these observations likely derive from viruses that resided upon the organisms' exterior surface, caught in epithelial mucus or infecting bacteria there.

The viral group comprising the greatest proportion of sequences in libraries-the phycodnaviruses-was significantly higher $(p<0.0001$, Student's $t$-test, $d f=38)$ compared to the next most well-represented group, the parvoviruses, which in turn was significantly higher $(p<0.000001$, Student's $t$ test, $d f=38$ ) than the next most abundant group, the retroviruses. Our observation of bidnaviruses and asfiviruses in Echinodermata, circoviruses, and densoviruses in Chordata, iridoviruses in Echinodermata and Chordata, and arteriviruses and nucleopolyhedroviruses in Arthropoda extend the potential host ranges of these viral families. Of viral groups, only the totiviruses (in Cnidaria), nimaviruses (in Urochordata), and arteriviruses (in Arthropods) were unique to the phyla sampled, with the remaining viral annotations shared between at least two phyla.

\section{Similarities and Differences between Viromes of Different Marine Invertebrate Phyla}

The viral assemblages of marine invertebrates are generally disparate both within and between host phyla (Tables 3, 4). Chordate-derived viromes are the most similar, at $69.4 \%$ mean similarity (Bray-Curtis similarity index), while arthropodderived viromes are the least similar, at $18.1 \%$. These differences could have resulted from differences in feeding patterns, as $P$. chilensis is a filter-feeder, while the arthropods studied are herbivores or detritivores. These observations could also

TABLE 2 | The number of contiguous sequences (viral, bacterial, archaeal, eukaryotic), annotated viral contigs, and percentage of viral contigs resulting from the sequencing of viromes from samples listed in Table 1.

\begin{tabular}{|c|c|c|c|c|}
\hline Sample & Phylum & Contiguous sequences & Viral contigs & $\%$ Viral contigs ( $\%$ ) \\
\hline Orchestoidea californiana & Arthropoda & $1,360,003$ & $1,068,508$ & 78.6 \\
\hline Peramphithoe femorata & Athropoda & 599,142 & 69,164 & 11.5 \\
\hline Neotrypaea californiensis & Arthropoda & 398,620 & 214,006 & 53.7 \\
\hline Halocaridina rubra & Arthropoda & 473,250 & 9820 & 2.1 \\
\hline Gorgonia ventalina $(\mathrm{H})$ & Cnidaria & 195,470 & 172,069 & 88.0 \\
\hline Gorgonia ventalina (D) & Cnidaria & 460,721 & 394,775 & 85.7 \\
\hline Pyura chilensis 1A & Chordata & 273,024 & 142,900 & 52.3 \\
\hline Pyura chilensis 2A & Chordata & 214,449 & 79,973 & 37.3 \\
\hline Pyura chilensis 2B & Chordata & 241,045 & 148,244 & 61.5 \\
\hline Pyura chilensis 3A & Chordata & 62,623 & 25,718 & 41.1 \\
\hline Pyura chilensis 4A & Chordata & $1,677,426$ & 628,094 & 37.4 \\
\hline Pyura chilensis 4B & Chordata & 655,771 & 462,093 & 70.5 \\
\hline Pyura chilensis 5A & Chordata & 786,281 & 296,976 & 37.8 \\
\hline Pyura chilensis 5B & Chordata & 683,419 & 473,197 & 69.2 \\
\hline
\end{tabular}

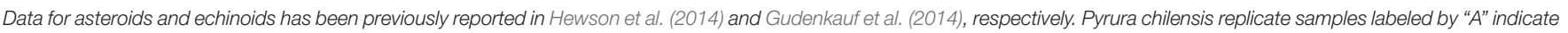
those prepared with GenomePlex" ${ }^{\odot}$, while those labeled with "B" indicate those prepared with GenomiPhi". 


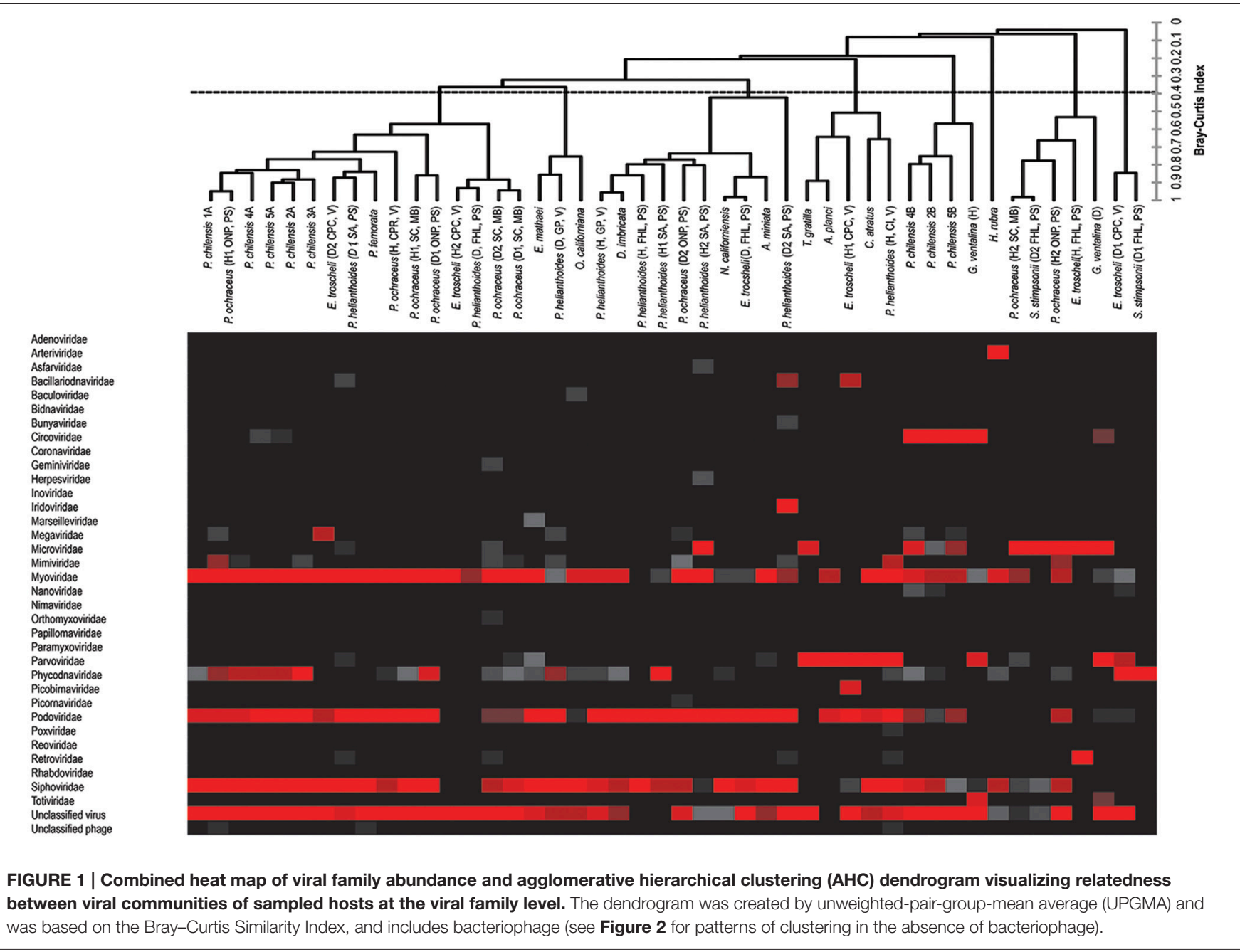

result from differences in motility, as $P$. chilensis is stationary throughout its lifespan, encountering the same types of environmental viruses, while the arthropods are motile and could be exposed to different viruses as they traverse novel environments.

While total viral assemblages of marine invertebrates are disparate in general, the non-bacteriophage echinoidea-derived viromes (i.e., including only the virus families which infect eukaryotes) are more similar to each other than to any other group, and are clearly separate from urochordate-derived viromes (Figure 2). Also, the individual asteroidea viromes are highly dissimilar to one another, a difference which could have resulted from the wide geographic range of sample collection and concomitant exposure to different sources of viruses.

The similarities and differences observed both within and between host phyla could have resulted from differences in location of sample collection, feeding patterns, host physiology, immune response, viral entry receptors, or active infection, although pathogenesis and immune activity is not the focus of this work. Further metagenomic studies should incorporate greater numbers and phyla of these organisms from various locations for greater statistical power and discrimination between these different variables.

\section{Trends in Viral Detection across Host Phyla}

Circoviruses were found in high proportion in diseased $G$. ventalina (cnidaria) and were found in low proportion in echinoderms (Figure 1). Interestingly, these viruses were completely absent from arthropod-derived viromes. Viruses from the Parvoviridae family are particularly widespread in marine invertebrate viromes, comprising a large proportion of those from echinoderms (both asteroidea and echinoidea), but a relatively low proportion in viromes of urochordates. Again, these viruses were completely absent from arthropod-derived viromes (Figure 1). Further investigation should clarify why circoviruses and parvoviruses were not detected in this host phylum. Phycodnaviruses were present in high proportions in arthropod, echinoderm, and urochordate-derived viromes, but were present in low proportion in viromes of cnidaria (Figure 1). These differences may suggest differential exposure of these hosts to infected algae in the surrounding water and these algae-associated viruses. Mimiviruses were detected in high 
TABLE 3 | Pair-wise matrix of mean similarity and standard error (in brackets) of total viromes (i.e., including bacteriophage) within and between host phyla, between asteroids and echinoids, and between GenomePlex and GenomiPhi prepared libraries (from Pyura chilensis urochordate samples).

\begin{tabular}{|c|c|c|c|c|c|c|}
\hline & Echinodermata & Arthropoda & Cnidaria & Chordata & Asteroidea & GenomiPhi \\
\hline Echinodermata & $28.1 \%$ [1.114\%] & $24.8 \%$ [2.175\%] & $26.0 \%$ [3.130\%] & $35.5 \%$ [1.564\%] & & \\
\hline Arthropoda & & $18.1 \%$ [4.515\%] & $15.4 \%$ [4.568\%] & $32.3 \%$ [4.741\%] & & \\
\hline Cnidaria & & & $47.7 \%$ & $38.2 \%$ [5.420\%] & & \\
\hline Chordata & & & & $69.4 \%$ [6.106\%] & & \\
\hline Echinoidea & & & & & $20.0 \%$ [1.617\%] & \\
\hline GenomePlex & & & & & & $30.8 \%$ [1.801\%] \\
\hline
\end{tabular}

TABLE 4 | Pair-wise matrix of mean similarity and standard error (in brackets) of non-bacteriophage viromes within and between host phyla, between asteroids and echinoids, and between GenomePlex and GenomiPhi prepared libraries (from Pyura chilensis urochordate samples).

\begin{tabular}{|c|c|c|c|c|c|c|}
\hline & Echinodermata & Arthropoda & Cnidaria & Chordata & Asteroidea & GenomiPhi \\
\hline Echinodermata & $23.2 \%$ [1.601\%] & $21.1 \%$ [3.360\%] & $21.9 \%[1.472 \%]$ & $24.3 \%$ [1.318\%] & & \\
\hline Arthropoda & & $19.2 \%$ [18.520\%] & $8.40 \%$ [5.927\%] & $37.7 \%$ [5.461\%] & & \\
\hline Cnidaria & & & $26.5 \%$ & $35.1 \%$ [5.920\%] & & \\
\hline Chordata & & & & $65.8 \%[10.113 \%]$ & & \\
\hline Echinoidea & & & & & $21.7 \%$ [3.465\%] & \\
\hline GenomePlex & & & & & & $6.2 \%$ [1.280\%] \\
\hline
\end{tabular}

proportion in four echinoderm samples (echinoidea), suggesting that amoeba species are present in/on these host species (Figure 1). Lastly, retroviruses were found in high proportions in two echinoderm samples (echinoidea), perhaps indicating active infection in these hosts (Figure 1). Future investigation should clarify the epidemiological importance of these observations in marine invertebrates as well as their physiological basis.

\section{Unexpected Viruses Found within Marine Invertebrates \\ Single-Stranded RNA Viruses}

It is surprising that RNA viruses were detected, as only DNA viruses were targeted using our approach. These could have been intermediate DNA stages after conversion from viral RNA to DNA in the host cell by reverse transcriptase enzymes. Arteriviruses were detected in Halocaridina rubra, with observations representing strong homology to arterivirus proteins since the match was stringent $(E$-value $=0.00)$. Arteriviruses have pleomorphic (usually icosahedral) enveloped capsids and linear, positive sense genomes that are 12$16 \mathrm{~kb}$ in length, encoding eight to twelve genes (Snijder et al., 2013). Isolated arteriviruses have only been found in mammals, although viruses from the order Nidovirales (to which arteriviruses belong) have also been found infecting shrimp, fish, and insects (Snijder et al., 2013). Arterivirus infection can result in a range of effects from total asymptomatic infection to fatal disease (Snijder et al., 2013).

\section{Single-Stranded DNA Viruses}

Previously characterized bacilladnaviruses have an enveloped icosahedral capsid and a closed circular genome of approximately $6.7 \mathrm{~kb}$ (Tomaru et al., 2011). These viruses infect diatoms from the phylum Bacillariophyta and their presence within metazoans (two P. helianthoides from Seattle Aquarium and three E. troscheli from Cape Roger Curtis) suggests they ingested or came into contact with infected diatoms. Sequence homology to bacilladnaviral proteins was strong, with $e$-values ranging from $1.57 \times 10^{-6}$ to $1.90 \times 10^{-34}$.

Bidnaviruses were detected in two asteroids, $P$. ochraceus from Cates Park Reef and E. troscheli from Cape Roger Curtis. They consist of non-enveloped spherical capsids enclosing two sets of complimentary linear genomes of 6.5 and $6 \mathrm{~kb}$ that encode four genes (Hu et al., 2013). Hits within these asteroids represent homologous proteins within the bidnaviral genomes, since they had low $e$-values $\left(2.24 \times 10^{-21}\right.$ and $\left.1.08 \times 10^{-8}\right)$. Bidnaviruses have only been detected previously in the insect Bombyx mori, where they are highly pathogenic.

Circoviruses were particularly widespread amongst the viromes and detected in cnidarians, urochordates, and echinoderms; until recently they were only known to exist in mammals, birds, arthropods and amphipods (Dunlap et al., 2013). They are non-enveloped, icosahedral viruses with a circular genome of about $2 \mathrm{~kb}$, and infection ranges from asymptomatic to fatal (Delwart and Li, 2012). An echinoderm circovirus from $E$. troscheli appears very similar to a circovirus from the crustacean Labidocera aestiva. G. ventalina circoviruses appear to be the most distantly related to crustacean, echinoderm, and tunicate circoviruses (Figure 3). All of these circoviruses were distantly related to mammalian and avian circoviruses yet distinct from cycloviruses.

Densoviruses (family Parvoviridae) are non-enveloped viruses with icosahedral capsids and linear genomes of $3-5 \mathrm{~kb}$ that encode two or three genes (Wang et al., 2010). Parvoviridae were known, until recently, to only infect vertebrates, arthropods, 


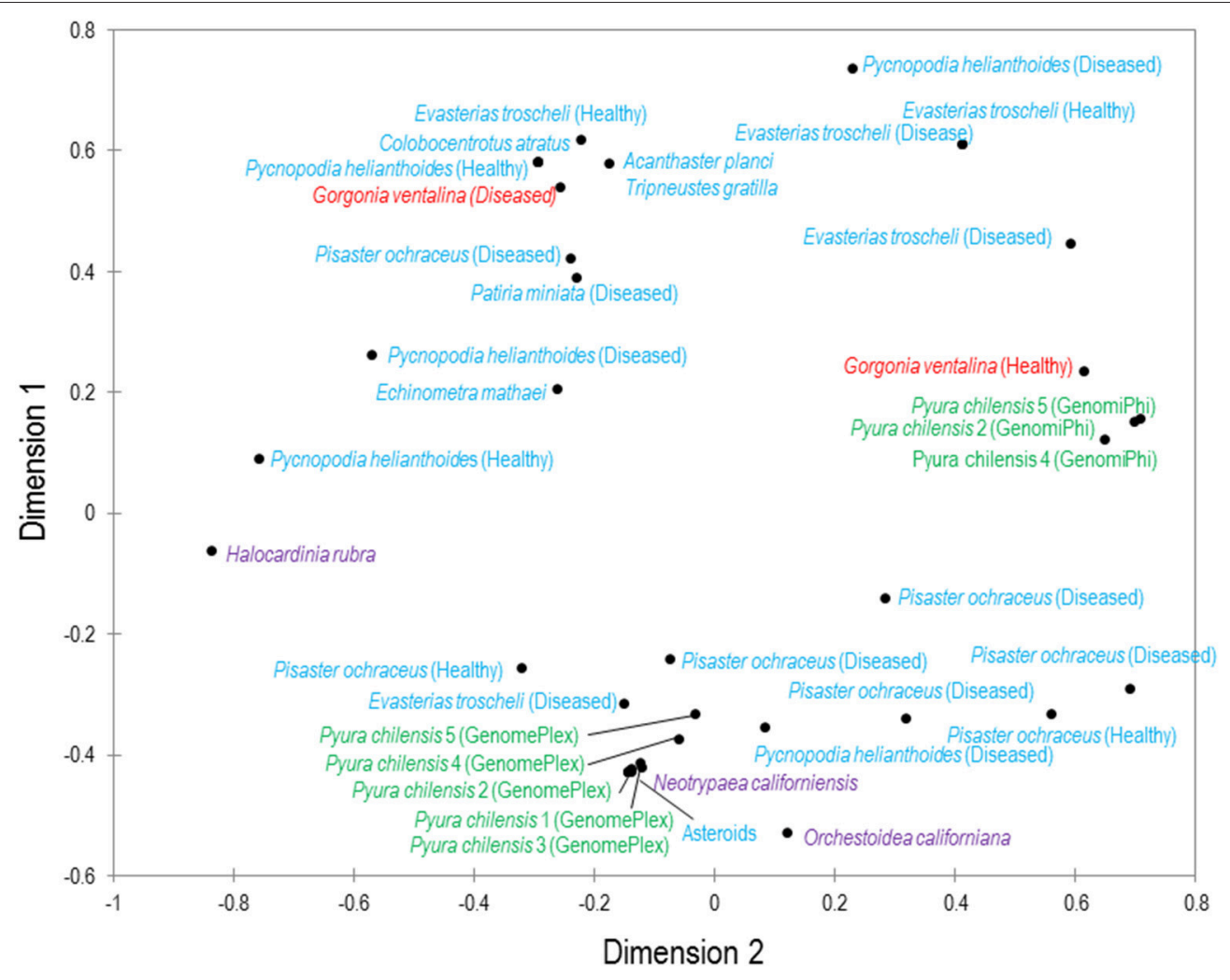

FIGURE 2 | Multiple dimensional scaling plot of viral metagenomes prepared from four phyla. MDS plot represents two-dimensional scaling analysis (absolute model, Kruskal's stress, random initial configuration, five repetitions, stop condition at 0.00001 convergence/500 iterations). The phyla are color-coded: blue are echinoderms, red are gorgonian octocorals, green are urochordates and purple are crustaceans. Bacteriophage and unclassified viruses are not included in this analysis.

and echinoderms (Gudenkauf et al., 2014; Hewson et al., 2014) but this study detected them within echinoderms, cnidarians, and urochordates. Infection may be asymptomatic (Berns and Parrish, 2007) or lead to mass mortality amongst populations like Hawaiian blue shrimp (Bell and Lightner, 1984). Phylogenetic analysis corroborates observations of virome similarity (Figure 3). Acanthaster planci and E. troscheli densoviruses appear to be closely related to each other and to insect densoviruses, again suggesting that echinoderm-associated viruses are similar to those associated with arthropods. P. chilensis densoviruses are somewhat distant from those of echinoderms or cnidarians. All densovirus-like sequences are distantly related to parvoviruses and bocaviruses. Parvoviruses (genus Parvovirus of the Parvoviridae family) contain two open reading frames while Bocaviruses (genus Bocavirus, also within Parvoviridae) contain three open reading frames, with the third located in the middle of the viral genome (Zhang et al., 2011; Cotmore et al., 2014). Densoviruses infect invertebrate hosts while parvoviruses and bocaviruses infect vertebrates (Cotmore et al., 2014).

\section{Double-Stranded DNA Viruses}

Asfiviruses were detected in two asteroids, P. ochraceus from Cates Park Reef and P. helianthoides from Seattle Aquarium (second healthy sample). They have been detected primarily in mammals (Rodríguez et al., 1996) but also in terrestrial arthropods (Labuda and Nuttall, 2004; Hubálek and Rudolf, 2012) and have enveloped icosahedral capsids enclosing a linear genome of $170-193 \mathrm{~kb}$ that encodes 70 genes (Dixon et al., 2013). Infection in arthropods is asymptomatic but results in severe hemorrhagic fever in mammals. These observations had relatively weak expect values $\left(8.10 \times 10^{-5}\right.$ and $\left.1.60 \times 10^{-8}\right)$ and hence may represent homologous proteins from asfiviruses or other organisms.

Nucleopolyhedroviruses (NPV's) along with granuloviruses comprise a suborder of Baculoviridae and were detected as a particularly strong hit in the amphipod Orchestoidea californiana (E-value of $1.24 \times 10^{-89}$ ). They have enveloped baculoshaped capsids enclosing a closed circular genome of 120$140 \mathrm{~kb}$ that encodes $100-180$ proteins (Blissard and Rohrmann, 1990; Thiem and Cheng, 2009; Hewson et al., 2011b). NPV's typically infect insects but a recent study found them heavily enriched in sea foam and kelp detritus (Thiem and Cheng, 2009; Hewson et al., 2011b). By inhabiting and consuming kelp detritus $O$. californiana could be hosting this virus and release desiccation-resistant multivirion capsids necessary for viral transmission. This would indicate that NPV's detected in the 2011 Hewson et al. study were most likely from amphipod hosts. 


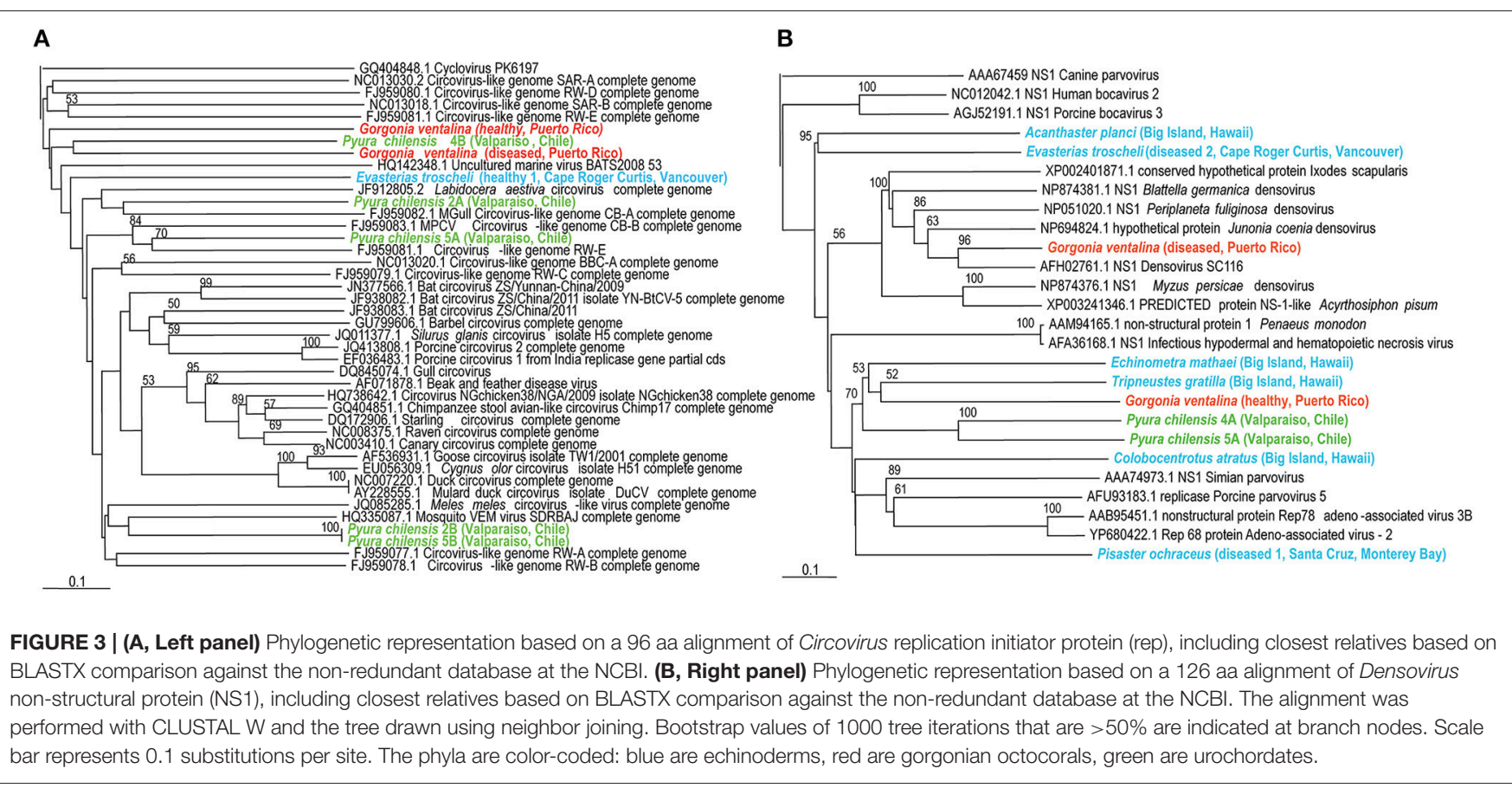

Iridoviruses have been found within insects, mollusks, crustacean, and cnidarians in previous studies (Williams, 2008; Weynberg et al., 2014), but were detected in Demasterias imbricata, $P$. helianthoides (second diseased sample from the Seattle Aquarium), E. troscheli (second diseased sample from Cates Park Reef), and GenomePlex-prepared P. chilensis samples from Chile. They may have enveloped or non-enveloped icosahedral capsids (depending on if they resulted from budding or release via lysis) and contain a linear genome of $140-303 \mathrm{~kb}$ that encodes a highly variable number of genes (Darai, 1989). These hits have strong homology to iridoviral proteins, with $e$ values of $5.51 \times 10^{-20}, 5.17 \times 10^{-10}, 2.63 \times 10^{-5}, 4.90 \times 10^{-15}$, and $5.24 \times 10^{-16}$, respectively.

Phycodnaviruses are enveloped icosahedral viruses with dsDNA genomes from 160 to $560 \mathrm{~kb}$ in length, encoding dozens of genes (Grimsley et al., 2012). These viruses infect algae, suggesting that their presence within echinoderms and tunicates indicates that these populations consumed infected algae. Phycodnaviruses associated with tunicates appeared distinct from those associated with echinoderms and all phycodnaviruses in invertebrate viromes were distinct from distantly related phycodnavirus genotypes like Ectocarpus siliculosis virus (Figure 4).

Pseudomonas bacteriophages were also particularly widespread amongst the viromes and were detected in echinoderms, crustaceans, and tunicates (Figure 1). These phages are mostly from the Myoviridae family and have non-enveloped icosahedral capsids enclosing genomes of 33-244 kb encoding 40-415 proteins (Drulis-Kawa et al., 2014). Pseudomonas phages infect the Pseudomonas genus of $\gamma$-proteobacteria and their presence reveals the existence of Pseudomonas within or associated with hosts. Those from
$P$. ochraceus appear distinct from those associated with $P$. chilensis. All phage were distantly related to Pseudomonas phage PAKP1 and distinct from Vibrio phage KVP40.

Persicivirga bacteriophages are recently characterized as part of the Siphoviridae family, with non-enveloped icosahedral capsids containing genomes of $35 \mathrm{~kb}$, encoding seven proteins (Kang et al., 2012). These phages infect the Persicivirga genus of the Flavobacteriaceae family of the Bacteroidetes phylum and their presence within echinoderms, crustaceans, and tunicates demonstrates the existence of Persicivirga within or associated with these organisms. Persicivirga can degrade complex polysaccharides produced by algae, suggesting that their presence is closely linked to marine algae (Kang et al., 2012). Phylogenetic analysis corresponds with observations of virome similarity (Figure 5) as a clear separation exists between those associated with $P$. chilensis and E. troscheli. Other Persicivirga phage-like sequences are spurious hits; those from $P$. ochraceus (Friday Harbor Lab, diseased 2 Santa Cruz, healthy 1 Santa Cruz, and Olympic National Park), P. helianthoides, P. chilensis (1A, 2A, 4A, 4B), and E. troscheli (diseased 1 Cape Roger Curtis and Friday Harbor Lab) appeared most related to Pseudoalteromonas phage RIO-1, indicating that these phages are most likely phage of $\gamma$-proteobacteria like Pseudoalteromonas. P. chilensis 5B, and $P$. ochraceus (diseased 1, Santa Cruz) phages appeared related to Synechococcus phage S-CBS4 and are most likely not bacteriophages of Persicivirga or Pseudoalteromonas.

\section{Effect of Library Preparation Method on Metagenomic Composition}

Viromes prepared using two different library preparation methods are highly dissimilar (Figures 1, 2). The mean 


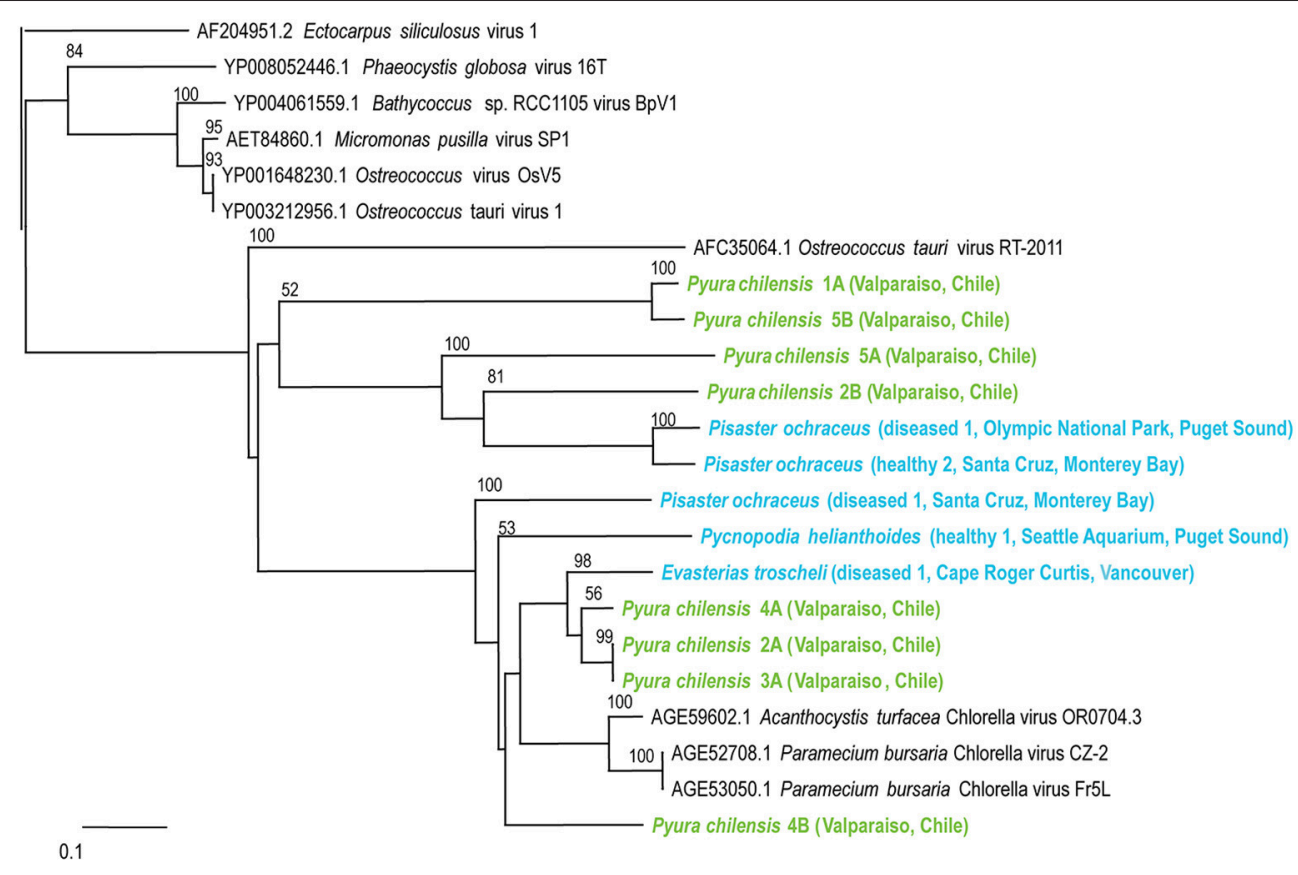

FIGURE 4 | Phylogenetic representation based on a 76 aa alignment of Phycodnavirus adenosylcobalamin-dependent ribonucleoside-triphosphate reductase protein, including closest relatives based on BLASTX comparison against the non-redundant database at the NCBI. The alignment was performed with CLUSTAL W and the tree drawn using neighbor joining. Bootstrap values of 1000 tree iterations that are $>50 \%$ are indicated at branch nodes. Scale bar represents 0.1 substitutions per site. The phyla are color-coded: blue are echinoderms, green are urochordates.

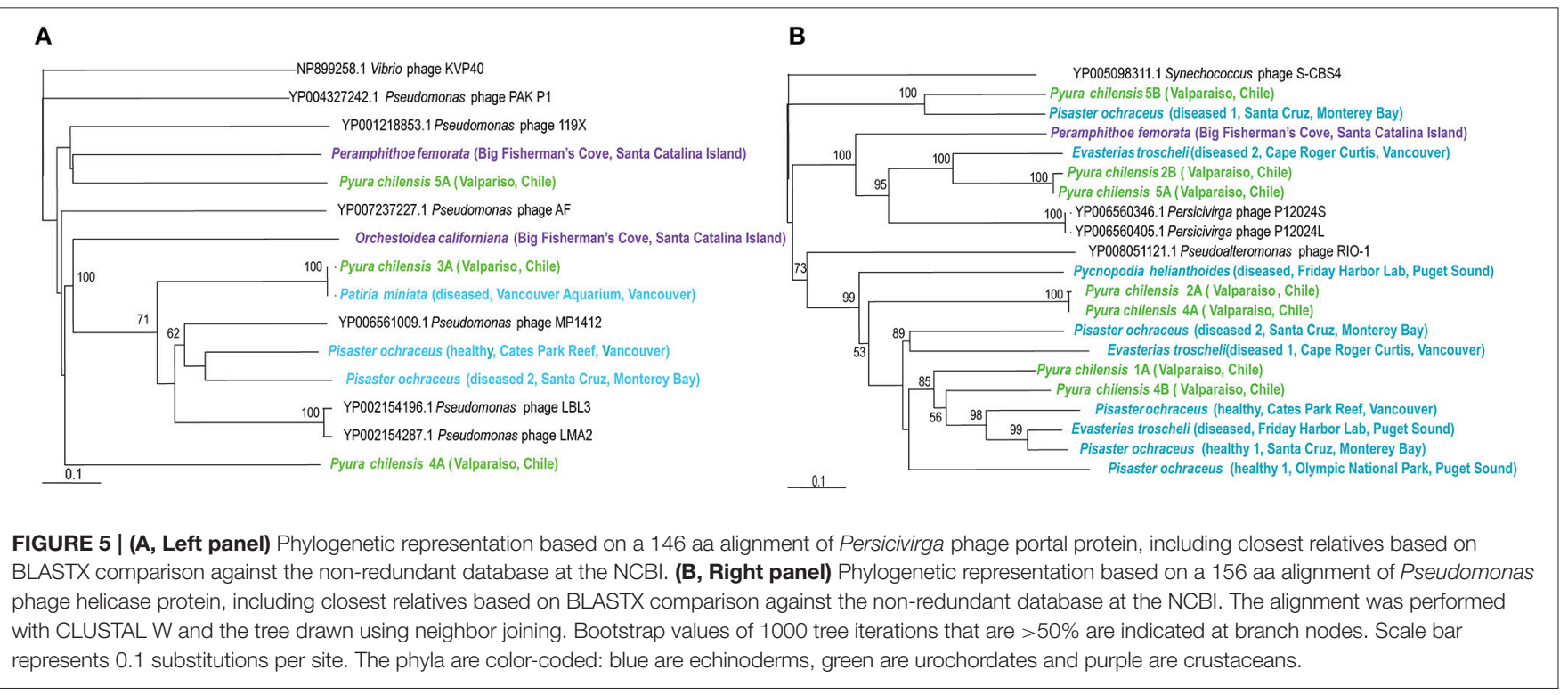

between-library method similarity was significantly different $\left(p=10^{-23}\right.$, Student's $t$-test, $\left.d f=15\right)$ to within-library method similarity. GenomiPhi (which utilizes multiple displacement amplification) appears to bias results in favor of circular single stranded viruses, confirming the results of previous work $(\mathrm{Ng}$ et al., 2011). Circoviruses were detected in abundances several orders of magnitude larger within GenomiPhi-prepared samples than in those prepared with GenomePlex, comprising $4.09 \%$ of the P. chilensis sample 4 virome prepared with GenomiPhi and only $0.01 \%$ of the virome prepared with GenomePlex. In contrast, phycodnaviruses were under-represented in the GenomiPhi library, representing only $0.02 \%$ of reads (compared to $0.93 \%$ of reads in the GenomePlex-prepared library). Differences also resulted from GenomiPhi's failure to amplify several types 
of linear dsDNA viruses which were detected in libraries prepared by GenomePlex. For instance, the virome derived from GenomiPhi-prepared $P$. chilensis sample 4 lacked all hits to Iridoviridae, Marseilleviridae, and Nimaviridae linear dsDNA virus families that were present within the GenomePlex-prepared sample. Overall, there were fewer circular ssDNA viruses, and more strains of linear dsDNA viruses in viromes from $P$. chilensis that were prepared with GenomePlex.

Our result corroborates previous studies that found that GenomiPhi biases viromes in favor of circular single stranded DNA viruses, resulting in variable coverage of viral communities, leaving entire families unamplified (Kim and Bae, 2011; Marine et al., 2014). These results reflect the fact that the phi29 DNA polymerase preferentially amplifies genomic regions associated with circular ssDNA viruses during initial priming events (Dichosa et al., 2012). We agree with previous work and suggest that researchers choose an amplification strategy that will minimally bias results if viral community proportions are to be studied. If possible, PCR-free approaches will result in the least bias. However, if viral detection is the only goal of a study, it would be wise to use both GenomePlex and GenomiPhi to ensure all linear ssDNA and circular ssDNA viruses are detected.

\section{CONCLUSIONS}

This study indicates that viromes of marine invertebrates are generally disparate both within and between host phyla. Urochordates have the most similar viromes, while arthropods have the least. Non-bacteriophage echinoidea viromes appear most similar by multidimensional scaling analysis and distinct from those derived from urochordates. Asteroidea, cnidaria, and arthropod-derived non-bacteriophage viromes are highly disparate. Several virus families were observed in certain

\section{REFERENCES}

Bates, A. E., Hilton, B. J., and Harley, C. D. (2009). Effects of temperature, season and locality on wasting disease in the keystone predatory sea star Pisaster ochraceus. Dis. Aquat. Organ. 86, 245-251. doi: 10.3354/dao02125

Becker, P., Gillan, D. C., and Eeckhaut, I. (2007). Microbiological study of the body wall lesions of the echinoid Tripneustes gratilla. Dis. Aquat. Organ. 77, 73-82. doi: 10.3354/dao01821

Becker, P. T., Gillan, D. C., and Eeckhaut, I. (2009). Characterization of the bacterial community associated with body wall lesions of Tripneustes gratilla (Echinoidea) using culture-independent methods. J. Invertebr. Pathol. 100, 127-130. doi: 10.1016/j.jip.2008.11.002

Bell, T. A., and Lightner, D. V. (1984). IHHN virus - infectivity and pathogenicity studies in Penaeus stylirostris and Penaeus vannamei. Aquaculture 38, 185-194. doi: 10.1016/0044-8486(84)90142-X

Berke, S. K. (2010). Functional groups of ecosystem engineers: a proposed classification with comments on current issues. Integr. Comp. Biol. 50, 147-157. doi: $10.1093 /$ icb/icq077

Berns, K., and Parrish, C. R. (2007). "Parvoviridae," in Field's Virology, eds D. M. Knipe, P. M. Howley, D. E. Griffin, R. A. Lamb, M. A. Martin, B. Roizman, and S. E. Straus (Philadelphia, PA: Lippincott Williams and Wilkins), 2437-2477.

Blissard, G. W., and Rohrmann, G. F. (1990). Baculovirus diversity and molecular ecology. Annu. Rev. Entomol. 35, 127-155. doi: 10.1146/annurev.en.35.010190.001015 host phyla but not others, and viruses of Parvoviridae and Phycodnaviridae were found in all phyla except arthropoda. The viral communities of many marine invertebrates have not been investigated but may be influencing host ecology, and this study may provide some starting points for further investigation into similarities and differences observed. These may be due to cellular, immunological, geographical, and ecological niche differences amongst these host phyla. Additionally, several viral families were observed within viromes that have not been detected in these host phyla in previous investigation. Finally, this paper confirms previous results indicating substantial differences between viromes built by multiple displacement amplification and other library preparation approaches by describing artifactual differences in community composition and representation introduced by the two methods.

\section{AUTHOR CONTRIBUTIONS}

$\mathrm{IH}$, and BG designed and performed laboratory analyses, analyzed data, and helped to write the paper.

\section{ACKNOWLEDGMENTS}

The authors are grateful to Ernesto Weil (University of Puerto Rico), David Needham, and Wiebke Ziebis (University of Southern California), Senifa Annandale (University of Hawaii, Hilo), David Tapia Espinoza, Yoanna Eissler, and Juan Kuznar (University of Valparaiso), and Nelson Hairston (Cornell University) for sample collection. The authors are also grateful to James Eaglesham (Cornell University) for assistance with virome preparation. This work was supported by NSF grants OCE-1356964, OCE-1537111, DEB-1028898, and OCE-1049670 awarded to $\mathrm{IH}$ and a grant from the Mario Einaudi Center for International Studies at Cornell University.

Bluhm, B. A., Piepenburg, D., and von Juterzenka, K. (1998). Distribution, standing stock, growth, mortality and production of Strongylocentrotus pallidus (Echinodermata: Echinodea) in the northern Barents Sea. Polar Biol. 20, 325-334. doi: 10.1007/s003000050310

Carpenter, R. C. (1990). Mass mortality of Diadema antillarum. I. Long-term effects on sea urchin population-dynamics and coral reef algal communities. Mar. Biol. 104, 67-77. doi: 10.1007/BF01313159

Cerrano, C. B., Bavastrello, G., Nike Bianchi, C., Cattaneo-vietti, R., Bava, S., Morganti, C., et al. (2000). A catastrophic mass-mortality episode of gorgonia and other organisms in the Ligurian Sea (North-western Mediterranean), summer 1999. Ecol. Lett. 3, 284-293. doi: 10.1046/j.1461-0248.2000. 00152.x

Cotmore, S. F., Agbandje-McKenna, M., Chiorini, J. A., Mukha, D. V., Pintel, D. J., Qiu, J., et al. (2014). The family Parvoviridae. Arch. Virol. 159, 1239-1247. doi: 10.1007/s00705-013-1914-1

Darai, G. (1989). Molecular Biology of Iridoviruses. Philadelphia, PA: Kluwver Academic Publishers.

Delwart, E., and Li, L. (2012). Rapidly expanding genetic diversity and host range of the Circoviridae viral family and other Rep encoding small circular ssDNA genomes. Virus Res. 164, 114-121. doi: 10.1016/j.virusres.2011. 11.021

Dichosa, A. E., Fitzsimons, M. S., Lo, C. C., Weston, L. L., Preteska, L. G., Snook, J. P., et al. (2012). Artificial polyploidy improves bacterial single cell genome recovery. PLoS ONE 7:e37387. doi: 10.1371/journal.pone.0037387 
Dixon, L. K., Chapman, D. A., Netherton, C. L., and Upton, C. (2013). African swine fever virus replication and genomics. Virus Res. 173, 3-14. doi: 10.1016/j.virusres.2012.10.020

Drulis-Kawa, Z., Olszak, T., Danis, K., Majkowska-Skrobek, G., and Ackermann, H. W. (2014). A giant Pseudomonas phage from Poland. Arch. Virol. 159, 567-572. doi: 10.1007/s00705-013-1844-y

Dunlap, D. S., Ng, T. F., Rosario, K., Barbosa, J. G., Greco, A. M., Breitbart, M., et al. (2013). Molecular and microscopic evidence of viruses in marine copepods. Proc. Natl. Acad. Sci. U.S.A. 110, 1375-1380. doi: 10.1073/pnas.12165 95110

Gil-Agudelo, D. L., Myers, C., Smith, G. W., and Kim, K. (2006). Changes in the microbial communities associated with Gorgonia ventalina during aspergillosis infection. Dis. Aquat. Organ. 69, 89-94. doi: 10.3354/dao0 69089

Goffredi, S. K., Jones, W. J., Ehrlich, H., Springer, A., and Vrijenhoek, B. C. (2008). Epibiotic bacteria associated with the recently discovered Yeti crab, Kiwi hirsutai. Environ. Microbiol. 10, 2623-2634. doi: 10.1111/j.14622920.2008.01684.x

Grimsley, N. H., Thomas, R., Kegel, J. U., Jacquet, S., Moreau, H., and Desdevises, Y. (2012). Genomics of algal host-virus interactions. Adv. Bot. Res. 64, 343-381. doi: 10.1016/B978-0-12-391499-6.00009-8

Gudenkauf, B. M., Eaglesham, J. B., Aragundi, W. M., and Hewson, I. (2014). Discovery of urchin-associated densoviruses (family Parvoviridae) in coastal waters of the Big Island, Hawaii. J. Gen. Virol. 95, 652-658. doi: 10.1099/vir.0.060780-0

Guri, M., Durand, L., Cueff-Gauchard, V., Zbinden, M., Crassous, P., Shillito, B., et al. (2012). Acquisition of epibiotic bacteria along the life cycle of the hydrothermal shrimp Rimicaris exoculata. ISME J. 6, 597-609. doi: 10.1038/ismej.2011.133

Hewson, I., Brown, J. M., Burge, C. A., Couch, C. S., LaBarre, B. A., Mouchka, M. E., et al. (2011a). Description of viral assemblages associated with the Gorgonia ventalina holobiont. Coral Reefs 31, 487-491. doi: 10.1007/s00338-0110864-x

Hewson, I., Brown, J. M., Gitlin, S. A., and Doud, D. F. (2011b). Nucleopolyhedrovirus detection and distribution in terrestrial, freshwater, and marine habitats of Appledore Island, Gulf of Maine. Microb. Ecol. 62, 48-57. doi: 10.1007/s00248-011-9856-1

Hewson, I., Button, J. B., Gudenkauf, B. M., Miner, B., Newton, A. L., Gaydos, J. K., et al. (2014). Densovirus associated with sea-star wasting disease and mass mortality. Proc. Natl. Acad. Sci. U.S.A. 111, 17278-17283. doi: 10.1073/pnas.1416625111

Hewson, I., Eaglesham, J. B., Hook, T. O., LaBarre, B. A., Sepulveda, M. S., Thompson, P. D., et al. (2013). Investigation of viruses in Diporeia spp. from the Laurentian Great Lakes and Owasco Lake as potential stressors of declining populations. J. Great Lakes Res. 39, 499-506. doi: 10.1016/j.jglr.2013. 06.006

Hu, Z. Y., Li, G. H., Li, G. T., Yao, Q., and Chen, K. P. (2013). Bombyx mori bidensovirus: the type species of the new genus Bidensovirus in the new family Bidnaviridae. Chin. Sci. Bull. 58, 4528-4532. doi: 10.1007/s11434-013-5876-1

Hubálek, Z., and Rudolf, I. (2012). Tick-borne viruses in Europe. Parasitol. Res. 111, 9-36. doi: 10.1007/s00436-012-2910-1

Jangoux, M. (1987). Diseases of Echinodermata. I. Agents microorganisms and protistans. Dis. Aquat. Organ. 2, 147-162. doi: 10.3354/dao002147

Kang, I., Jang, H., and Cho, J. C. (2012). Complete genome sequences of two Persicivirga bacteriophages, P12024S and P12024L. J. Virol. 86, 8907-8908. doi: 10.1128/JVI.01327-12

Kim, K. H., and Bae, J. W. (2011). Amplification methods bias metagenomic libraries of uncultured single-stranded and double-stranded DNA viruses. Appl. Environ. Microbiol. 77, 7663-7668. doi: 10.1128/AEM. 00289-11

Labuda, M., and Nuttall, P. A. (2004). Tick-borne viruses. Parasitology 129(Suppl.), S221-S245. doi: $10.1017 /$ S0031182004005220

Lessios, H. A. (1988). Mass mortality of Diadema antillarum in the Caribbean: what have we learned? Annu. Rev. Ecol. Syst. 19, 371-393. doi: 10.1146/annurev.es.19.110188.002103

Lessios, H. A., Robertson, D. R., and Cubit, J. D. (1984). Spread of Diadema mass mortality through the Caribbean. Science 226, 335-337. doi: $10.1126 /$ science. 226.4672 .335
Marine, R., McCarren, C., Vorrasane, V., Nasko, D., Crowgey, E., Polson, S. W., et al. (2014). Caught in the middle with multiple displacement amplification: the myth of pooling for avoiding multiple displacement amplification bias in a metagenome. Microbiome 2:3. doi: 10.1186/2049-2618-2-3

Mengoni, A., Focardi, A., Bacci, G., and Ugolini, A. (2013). High genetic diversity and variability of bacterial communities associated with the sandhopper Talitrus saltator (Montagu) (Crustacea, Amphipoda). Est. Coast. Shelf Sci. 131, 75-82. doi: 10.1016/j.ecss.2013.08.011

Munn, C. B. (2006). Viruses as pathogens of marine organisms - from bacteria to whales. J. Mar. Biol. Assoc. UK 86, 453-467. doi: 10.1017/S00253154060 $1335 \mathrm{X}$

Ng, T. F. (2010). Discovery of Novel Viruses from Animals, Plants, and Insect Vectors using Viral Metagenomics. Graduate School Theses and Dissertations. University of South Florida.

Ng, T. F., Manire, C., Borrowman, K., Langer, T., Ehrhart, L., and Breitbart, M. (2009). Discovery of a novel single-stranded DNA virus from a sea turtle fibropapilloma by using viral metagenomics. J. Virol. 83, 2500-2509. doi: 10.1128/JVI.01946-08

Ng, T. F. F., Duffy, S., Polston, J. E., Bixby, E., Vallad, G. E., and Breitbart, M. (2011). Exploring the diversity of plant DNA viruses and their satellites using vectorenabled metagenomics on whiteflies. PLoS ONE 6:e19050. doi: 10.1371/journal. pone. 0019050

Nunan, L. M., Pantoja, C. R., Gomez-Jimenez, S., and Lightner, D. V. (2013). "Candidatus Hepatobacter penaei," an intracellular pathogenic enteric bacterium in the hepatopancreas of the marine shrimp xi (Crustacea: Decapoda). Appl. Environ. Microbiol. 79, 1407-1409. doi: 10.1128/AEM. 02425-12

Page, R. D. (1996). TreeView: an application to display phylogenetic trees on personal computers. Comput. Appl. Biosci. 12, 357-358.

Paine, R. T. (1969). The Pisaster-Tegula interaction: prey patches, predator food preference, and intertidal community structure. Ecology 50, 950-961. doi: $10.2307 / 1936888$

Pérez-Matos, A. E., Rosado, W., and Govind, N. S. (2007). Bacterial diversity associated with the Caribbean tunicate Ecteinascidia turbinata. Antonie Van Leeuwenhoek. 92, 155-164. doi: 10.1007/s10482-007-9143-9

Rodríguez, F., Fernández, A., Pérez, J., Mártin de las Mulas, J., Sierra, M. A., and Jover, A. (1996). African swine fever: morphopathology of a viral hemorrhagic disease. Vet. Rec. 139, 249-254. doi: 10.1136/vr.139.11.249

Rosario, K., Dayaram, A., Marinov, M., Ware, J., Kraberger, S., Stainton, D., et al. (2012). Diverse circular ssDNA viruses discovered in dragonflies (Odonata: Epiprocta). J. Gen. Virol. 93, 2668-2681. doi: 10.1099/vir.0.04 5948-0

Rosario, K., Marinov, M., Stainton, D., Kraberger, S., Wiltshire, E. J., Collings, D. A., et al. (2011). Dragonfly cyclovirus, a novel single-stranded DNA virus discovered in dragonflies (Odonata: Anisoptera). J. Gen. Virol. 92, 1302-1308. doi: 10.1099/vir.0.030338-0

Snijder, E. J., Kikkert, M., and Fang, Y. (2013). Arterivirus molecular biology and pathogenesis. J. Gen. Virol. 94, 2141-2163. doi: 10.1099/vir.0.056341-0

Suttle, C. A. (2005). Viruses in the sea. Nature 437, 356-361. doi: 10.1038 /nature 04160

Suttle, C. A. (2007). Marine viruses-major players in the global ecosystem. Nat. Rev. Microbiol. 5, 801-812. doi: 10.1038/nrmicro1750

Thiem, S. M., and Cheng, X.-W. (2009). Baculovirus host-range. Virol. Sin. 24, 436-457. doi: 10.1007/s12250-009-3058-8

Thompson, J. D., Higgins, D. G., and Gibson, T. J. (1994). Clustal-W - Improving the sensitivity of progressive multiple sequence alignment through sequence weighting, position-specific gap penalties and weight matrix choice. Nucleic. Acids Res. 22, 4673-4680. doi: 10.1093/nar/22.22.4673

Thurber, R. V., Haynes, M., Breitbart, M., Wegley, L., and Rohwer, F. (2009). Laboratory procedures to generate viral metagenomes. Nat. Protoc. 4, 470-483. doi: $10.1038 /$ nprot.2009.10

Tomaru, Y., Takao, Y., Suzuki, H., Nagumo, T., Koike, K., and Nagasaki, K. (2011). Isolation and characterization of a single-stranded DNA virus infecting Chaetoceros lorenzianus Grunow. Appl. Environ. Microbiol. 77, 5285-5293. doi: 10.1128/AEM.00202-11

Wang, F., Wei, Y., Zhu, C., Huang, X., Xu, Y., Yu, L., et al. (2010). Novel parvovirus sublineage in the family of Parvoviridae. Virus Genes 41, 305-308. doi: 10.1007/s11262-010-0506-3 
Weynberg, K. D., Wood-Charlson, E. M., Suttle, C. A., and van Oppen, M. J. H. (2014). Generating viral metagenomes from the coral holobiont. Front. Microbiol. 5:206. doi: 10.3389/fmicb.2014.00206

Williams, T. (2008). Natural invertebrate hosts of iridoviruses (Iridoviridae). Neotrop. Entomol. 37, 615-632. doi: 10.1590/S1519-566X2008000600001

Wommack, K. E., and Colwell, R. R. (2000). Virioplankton: viruses in aquatic ecosystems. Microbiol. Mol. Biol. Rev. 64, 69-114.

Zhang, H. B., Huang, L., Liu, Y. J., Lin, T., Sun, C. Q., Deng, Y., et al. (2011). Porcine bocaviruses: genetic analysis and prevalence in Chinese swine population. Epidemiol. Infect. 139, 1581-1586. doi: 10.1017/S0950268811000847
Conflict of Interest Statement: The authors declare that the research was conducted in the absence of any commercial or financial relationships that could be construed as a potential conflict of interest.

Copyright $\odot 2016$ Gudenkauf and Hewson. This is an open-access article distributed under the terms of the Creative Commons Attribution License (CC BY). The use, distribution or reproduction in other forums is permitted, provided the original author(s) or licensor are credited and that the original publication in this journal is cited, in accordance with accepted academic practice. No use, distribution or reproduction is permitted which does not comply with these terms. 